\title{
SEQÜÊNCIAS E TRATOS DE SISTEMAS DEPOSICIONAIS DO GRUPO ITARARÉ, NORTE DO ESTADO DO PARANÁ
}

\author{
FERNANDO FARIAS VESELY ${ }^{1} \&$ MARIO LUIS ASSINE ${ }^{2}$
}

\begin{abstract}
DEPOSITIONAL SEQUENCES AND SYSTEM TRACTS IN THE CARBONIFEROUS-PERMIAN GLACIAL ITARARÉ GROUP, SOUTHERN BRAZIL A representative vertical stratigraphic section about $800 \mathrm{~m}$ thick was measured in outcrops of the Carboniferous-Permian Itararé Group in northern Paraná State. Five depositional sequences bounded by disconformities were recognized and their facies associations described. The outcrop section shows good correlation with well logs and the sequences may be traceable over 400 kilometers across the basin in a EW depositional strike section. The five sequences have the same basic stratigraphic signature, which represents the glaciomarine sedimentary response to advance and retreat of glaciers. Ideally, three successive facies associations would compose each sequence, but the lower and upper ones may be absent. The lower facies association occurs only in the two lowermost sequences and includes subglacial facies as tillites and boulder conglomerates (glacial maximum system tract). The subglacial facies are covered by conglomerates and sandstones, which in turn are overlain by diamictites, turbidites and finely laminated facies with dropstones, composing a typical retrogradational facies stacking resulting from deglaciation (deglaciation system tract). Lying directly over the disconformities when subglacial facies do not occur, the deglaciation facies association is present in all sequences and represents the bulk of the stratigraphic record of the Itararé Group. Fine-grained laminated facies represent the record of the maximum glacial retreat during interglacial periods and contain the maximum seawater-flooding surface of each sequence. Coarsening upward facies association may be present in the upper part of the sequences, interpreted as the sedimentary response to the beginning of new glacial advances (glacial advance system tract). This facies association could represent progradation in highstand system tracts, but coastal and continental facies were not observed in the studied area.
\end{abstract}

Keywords: Itararé Group, Paraná Basin, Carboniferous-Permian glaciation, sequence stratigraphy, glacial system tracts

Resumo Um perfil vertical representativo de aproximadamente 800 metros de espessura foi levantado na faixa de afloramentos do Grupo Itararé no norte do Estado do Paraná. Foram reconhecidas cinco sequiências limitadas no topo e na base por disconformidades, cujas fácies e associações de fácies foram caracterizadas. O perfil de superfície foi correlacionado com perfis de poços profundos, onde as seqüências puderam ser rastreadas por uma distância de $400 \mathrm{Km}$ em uma seção EW paralela ao strike deposicional do Grupo Itararé. As cinco sequiências possuem a mesma assinatura estratigráfica, representada por fácies glácio-marinhas depositadas durante ciclos de avanço e recuo de geleiras. Três associações de fácies que se sucedem na vertical compõem o arcabouço estratigráfico das seqüências. sendo que as associações basal e superior podem estar ausentes. A associação basal ocorre somente nas duas sequiências inferiores e constitui-se de depósitos subglaciais, tais como tilitos e conglomerados ricos em matacões (trato de sistemas glacial máximo). As fácies subglaciais são cobertas por conglomerados e arenitos, os quais são sucedidos por diamictitos, turbiditos e finos laminados com clastos caídos, caracterizando típico empilhamento retrogradacional resultante de deglaciação (trato de sistemas de deglaciação). Repousando diretamente sobre as disconformidades quando da ausência das fácies subglaciais, a associação de deglaciação ocorre em todas as seqüências e compõe a maior parte do empilhamerto do Grupo Itararé. Finos laminados representam o registro do máximo recuo das geleiras durante períodos interglaciais e englobam as superfícies de inundação máxima de cada seqüência. Sucessões com granocrescência ascendente podem estar presentes acin.a'as superfícies de inundação máxima, sendo interpretadas como o início de novos avanços de geleiras (trato de sistemas de avanço gl...ial). Essa associação de fácies poderia representar progradação em tratos de sistemas de mar alto, mas fácies costeiras e continentais não foram observadas na área de estudo.

Palavras-chave: Bacia do Paraná, Grupo Itararé, glaciação permocarbonífera, estratigrafia de sequiências, tratos de sistemas glaciais

INTRODUÇÃO OGrupo Itararé (Neocarbonífero-Eopermiano) contém os registros sedimentares da glaciação gonduânica neopaleozóica na Bacia do Paraná. Vestígios da influência direta e indireta de geleiras estão impressos na sua complexa sucessão vertical de fácies. A baixa continuidade lateral e o alto grau de recorrência dos estratos, bem como a baixa resolução vertical dos esquemas biocronoestratigráficos concebidos para o Neopaleozóico da bacia, fazem com que o arcabouço estratigráfico regional da unidade esteja ainda mal delineado.

A identificação de três grandes seqüências ou ciclos estratigráficos foi a base para a classificação litoestratigráfica regional proposta por França \& Potter (1988), que subdividiram o Grupo Itararé nas formações Lagoa Azul, Campo Mourão e Taciba com base exclusivamente em dados de poços (Fig. 1). Dados de subsuperfície apresentam a vantagem de se dispor de registros contínuos de propriedades petrofísicas e de amostras de calha dos estratos perfurados, não havendo omissão de intervalos. Contudo, a caracterização das fácies é precária porque estruturas sedimentares só podem ser descritas em testemunhos, que são disponíveis em poucos intervalos. Além disso, as variações laterais

1- UNESP - Pós-Graduação em Geociências - Rio Claro-SP. Endereço atual: UFPR - Pós-Graduação em Geologia, Caixa Postal: 19027, CEP: 8153I-990. Centro Politécnico - Curitiba-PR (vesely@geologia.ufpr.br)

2 - UNESP - Departamento de Geologia Aplicada - Avenida 24-A, n 1515, CEP: 13506-900 - Rio Claro-SP (assine@rc.unesp.br). Endereço para correspondência: Mario Luis Assine - UNESP - Departamento de Geologia Aplicada. Avenida 24-A, 1515. Rio Claro-SP. CEP 13506-900) 
de fácies, tão comuns no Grupo Itararé, e a geometria dos corpos, não podem ser observadas.

Trabalhos na faixa aflorante têm sido limitados devido à descontinuidade dos afloramentos, dificultando o estabelecimento do empilhamento estratigráfico do Grupo Itararé. Têm permitido, por outro lado, o estudo detalhado das fácies e associações de fácies, sendo possível reconhecer a geometria dos corpos, as mudanças laterais de fácies e levantar atributos azimutais tais como sentidos de paleocorrentes, informações muito importantes na análise estratigráfica. Sob este aspecto, contribuíram para um melhor entendimento da arquitetura estratigráfica do Grupo Itararé os trabalhos de França et al. (1996), d'Avila (1999) e Canuto et al. (2001), que identificaram sequiências associadas a eventos de avanço e recuo de geleiras na faixa aflorante do sudeste do Estado do Paraná.

No presente trabalho são apresentados os resultados da análise estratigráfica do Grupo Itararé na região norte do Estado do Paraná (Fig. 2), realizada por Vesely (2001). Além de ser pouco estudada, a área ofereceu a possibilidade do levantamento de um perfil estratigráfico vertical representativo da unidade em superfície, fundamental para a correlação com perfis de poços perfurados a oeste e que serviram de base para a caracterização dos ciclos e para a subdivisão estratigráfica proposta por França \& Potter (1988).

Destacam-se os seguintes resultados alcançados: 1) levantamento de perfil estratigráfico vertical representativo da unidade em superfície; 2) correlação com perfis de poços perfurados a oeste; 3) definição de seqüiências deposicionais; 4) descrição das associações de fácies; 5) interpretação paleoambiental das associações de fácies e 6) caracterização dos tratos de sistemas deposicionais e suas relações com ciclos glaciais.

SEQÜÊECIAS DEPOSICIONAIS O Grupo Itararé repousa em discordância erosiva regional sobre folhelhos marinhos neodevonianos da Formação Ponta Grossa. Na área estudada, o contato com os estratos eopermianos da Formação Rio Bonito é erosivo, sendo dado ora com o Membro Triunfo (inferior) ora com o Membro Paraguaçu (médio), fato que se deve à descontinuidade lateral dos arenitos flúvio-deltaicos do Membro Triunfo.

A partir do levantamento sistemático de perfis estratigráficos verticais na rodovia BR-153, entre as cidades de Ventania e Ibaiti (Fig. 2), foi confeccionado um perfil composto do Grupo Itararé na área, representativo de uma seção total com aproximadamente 800 $m$ de espessura (Fig. 3). Com base nas sucessões verticais de fácies foram caracterizadas cinco sequiências deposicionais, denominadas 1, 2, 3, 4 e 5 (Fig. 3).

As sequiências são limitadas por variações abruptas no arranjo vertical de fácies, que constituem limites erosivos sobrepostos por tilitos subglaciais, conglomerados e/ou arenitos conglomeráticos. Tais descontinuidades registram eventos importantes de entrada de clásticos grossos no sítio deposicional e por isso foram utilizadas como superfícies-chave na análise de sequiências.

As cinco seqüências podem ser classificadas como seqüências deposicionais segundo a conceituação de Vail et al. (1977), pois compreendem sucessões verticais de fácies geneticamente relacionadas e limitadas no topo e na base por disconformidades. Possuem de 130 a 200 metros de espessura e, apesar de algumas peculiaridades, seus empilhamentos de fácies são bastante semelhantes (Fig. 3). O padrão geral é de granodecrescência ascendente, com fácies areno-conglomeráticas transicionando para fácies lamítico-arenosas. Após atingir valores máximos de argilosidade, o padrão se inverte em alguns casos, com a presença de pequenas sucessões com granocrescência ascendente no topo. Considerando um intervalo de tempo de 20 a 40 Ma para a sedimentação do Grupo Itararé (Santos et al. 1996), as cinco sequiências correspondem a episódios com duração média entre 4 e $8 \mathrm{Ma}$, correspondendo a ciclos de $3^{\mathrm{a}}$ ordem, conforme concepção de Vail et al. (1977).

A seqüiência 5 é a mais espessa e complexa, sendo constituída por dois ciclos de menor magnitude. Assim foi considerado, porque não foi constatada disconformidade na base do arenitos situados na parte média do intervalo, acima da SIM-5. Há, entretando, a possibilidade de duas seqüências diferentes terem sido englobadas na sequiência 5 , caso o contato dos arenitos seja a conformidade correlata de uma disconformidade lateralmente contigua. Pesquisas regionais são necessárias para elucidar a questão.

Para verificar a continuidade lateral das seqüências identificadas em superfície foi feita correlação com os poços 2-CS1-PR, 1-RO-1-PR, 2-AN-1-PR e 2-MO-1-PR, através de uma seção estratigráfica na direção aproximada leste-oeste (Fig. 4). Como superfície-chave para a correlação (datum) foi utilizado o pico mais radioativo do intervalo de maior argilosidade da seqüência 4 (superfície de inundação máxima), que se acha bem representado nos perfis de todos os poços analisados.

Como se pode observar na figura 4 , a espessura na faixa de afloramentos é similar à espessura do Grupo Itararé verificada nos poços. Isso em parte decorre do fato de que a seção é aproximadamente paralela ao strike deposicional do Grupo Itararé na área, já que as paleocorrentes medidas (Fig. 3) indicam mergulho deposicional para noroeste. Deve-se considerar também que o atual limite leste da Bacia do Paraná é erosivo, delineado pela presença do Arco de Ponta Grossa, não correspondendo ao que era a borda original da bacia no Permocarbonífero (Milani et al. 1998).

Nos poços situados a oeste também podem ser reconhecidas as cinco sequiências com padrão geral de argilosidade crescente para o topo. Seus limites são marcados por mudanças abruptas nas curvas dos perfis de raios-gama, cujas assinaturas geofísicas podem ser rastreadas em todos os poços, inclusive no poço 2 AN-1-PR, situado no extremo oeste do Estado do Paraná.

A sequiência I é a que apresenta maior variação de espessura, reflexo das irregularidades do paleo-relevo esculpido sobre o Grupo Paraná durante o Eocarbonífero, como mostrado por Assine (1996). A sequiência adelgaça-se na região do poço 2-MO-1-PR, tornandose mais espessa a oeste e atingindo espessura máxima no poço 2 AN-1-PR.

Variações nas taxas de subsidência, suprimento sedimentar e soerguimento glácio-isostático certamente contribuíram para a grande variação de espessura das sequiências 2,3 e 4 . Também importantes foram processos de erosão no topo das sucessões sedimentares, que geraram canais, posteriormente preenchidos por fácies areno-conglomeráticas das sequiências superpostas. Conforme já havia sido destacado no trabalho de França \& Potter (1988), a correlação estratigráfica nesse intervalo intermediário do Grupo Itararé é mais difícil, o que decorre da presença de abundantes intercalações de arenitos turbidíticos e de estruturas deformacionais em diferentes escalas, verificadas em diversos locais na faixa aflorante.

A seqüência 5 é a de melhor representatividade em subsuperfície, sendo seu limite basal facilmente identificado acima da seção de maior argilosidade da sequiência 4. A correlação nessa 


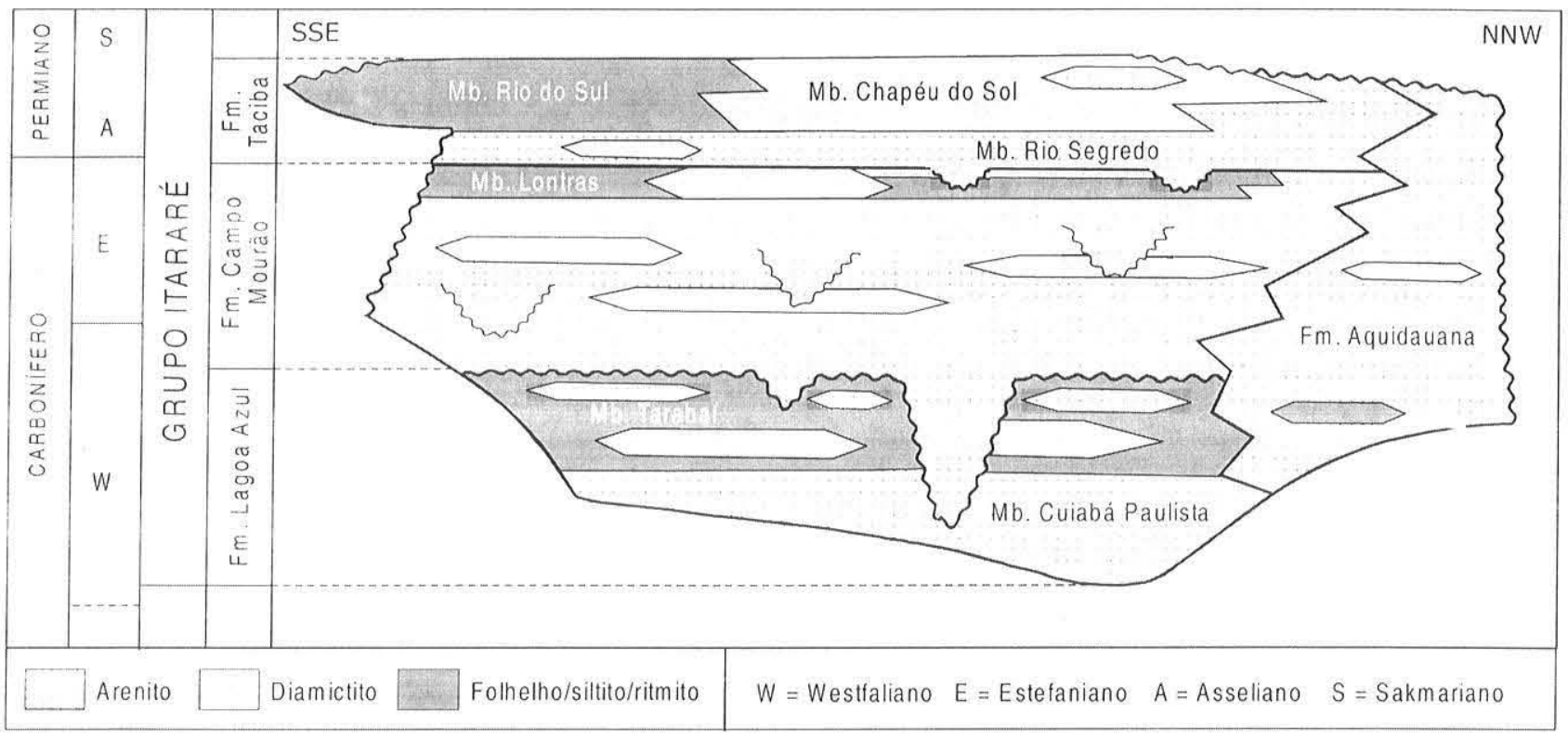

Figura I-Carta estratigráfica do Grupo Itararé (modificado de França \& Potter 1988 e França et al. 1996)

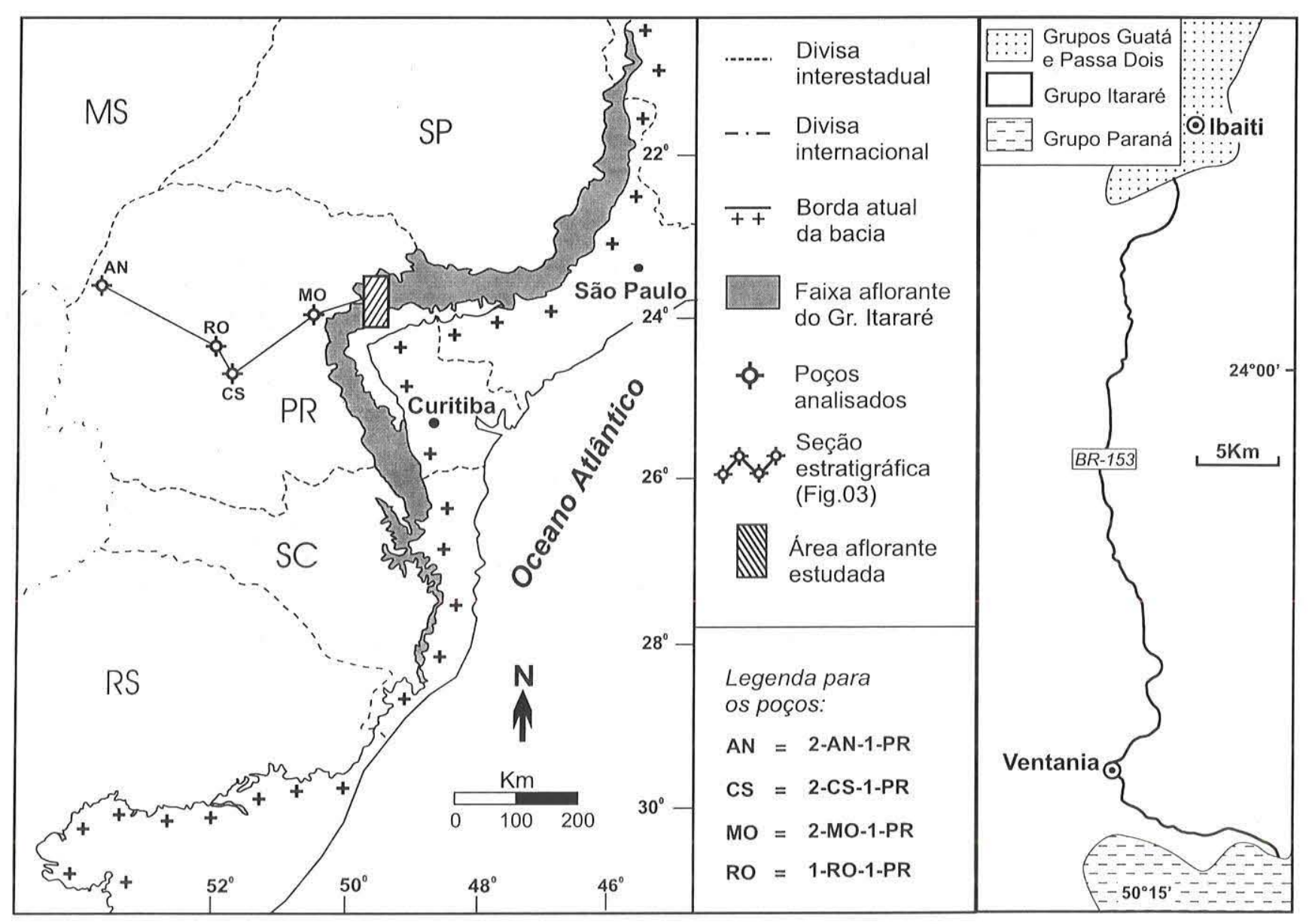

Figura 2 - Mapa de localização da faixa aflorante estudada, dos poços analisados e da seção estratigráfica de referência. 


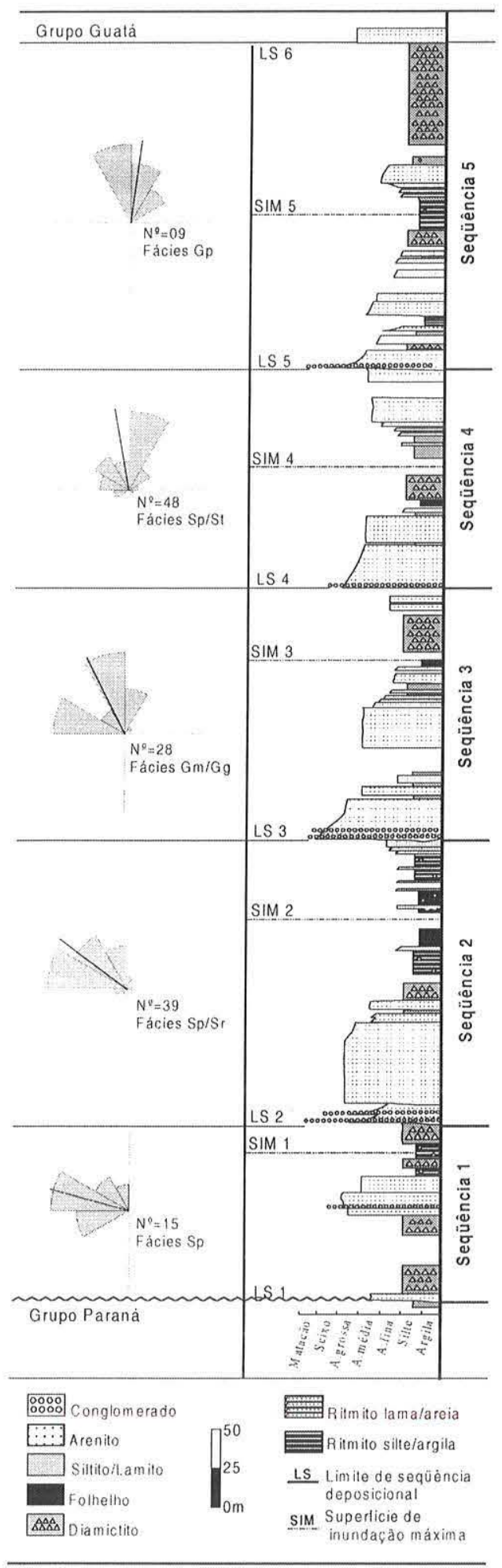

Figura 3 - Perfil estratigráfico composto, com a demarcação das cinco seqüencias deposicionais definidas neste trabalho. Os diagramas em rosetas à esquerda representam medidas de paleocorrentes efetuadas em planos frontais de estratificaçãol laminação cruzada (fácies St, Sp, Sr e Gp) e nos eixos dé imbricação de seixos/calhaus (fácies $G m e ~ G g$ ). A localização do perfil está indicada na figura 2. seqüência é facilitada pela persistência do seu padrão de granodecrescência ascendente em todos os poços e pelo espesso e lateralmente contínuo pacote de diamictitos no topo.

Em termos litoestratigráficos, a correlação apresentada mostra que as formações Lagoa Azul, Campo Mourão e Taciba (França \& Potter 1988) podem ser reconhecidas em superfície, pelo menos no nordeste do Estado do Paraná (Fig. 4). Tal conclusão difere de algumas interpretações anteriores que consideraram a ausência do terço inferior do Grupo Itararé na faixa aflorante (França \& Potter 1988, Eyles et al. 1993; Milani et al. 1994), mas é corroborada pela constatação feita por França et al. (1996), que identificaram palinomorfos de idade neocarbonífera (Westfaliano-Estefaniano) em afloramentos da Formação Campo do Tenente de Schneider et al. (1974). Horizontes correpondentes ao registro mais antigo do Grupo Itararé foram recentemente identificados em afloramentos no Estado de São Paulo por Souza (2000).

ASSOCIAÇÕES DE FÁCIES Três associações de fácies (A, B e C) compõem o arcabouço estratigráfico das seqüências identificadas. Cada associação comporta diversas fácies, nomeadas com base no código descritivo apresentado na Tabela 1 , apresentando padrão de variação textural vertical característico.

As associações apresentam-se numa sucessão vertical lógica, ocorrendo a associação A na parte inferior e as associações B e C na parte superior das seqüências (Fig. 5). Nem sempre, porém, a sucessão encontra-se completa, embora a associação B sempre esteja presente. Na sequiência 5 há recorrência das associações B e $\mathrm{C}$, representando possivelmente a interferência de um ciclo deposicional com ordem de grandeza menor do que a das sequiências discutidas neste trabalho.

Associação A Constituída por diamictitos maciços com alto grau de compactação (fácies Dmm) e conglomerados polimíticos desorganizados (fácies $\mathrm{Gc}$ ), por vezes portadores de matacões com até $50 \mathrm{~cm}$ de diâmetro (Fig. 6). Essa associação ocorre de

Tabela I-Fácies sedimentares identificadas (código adaptado de Eyles et al. 1983).

\begin{tabular}{|ll|}
\hline Código & Fácies \\
Gc & Conglomerado desorganizado ou caótico \\
Gm & Conglomerado maciço \\
Gg & Conglomerado com gradação normal \\
$\mathrm{Gp}$ & Conglomerado com estratificação cruzada planar \\
$\mathrm{Sh}$ & Arenito com estratificação plano-paralela \\
$\mathrm{Sp}$ & Arenito com estratificação cruzada planar \\
$\mathrm{St}$ & Arenito com estratificação cruzada acanalada \\
$\mathrm{Ss}$ & Arenito com estratificação cruzada sigmóide \\
$\mathrm{Sg}$ & Arenito com gradação normal \\
$\mathrm{Sm}$ & Arenito maciço \\
$\mathrm{Sd}$ & Arenito com deformação penecontemporânea \\
$\mathrm{Sr}$ & Arenito com ondulações de corrente ou laminação \\
$\mathrm{Fl} / \mathrm{Fld}$ & cruzada cavalgante \\
& Finos laminados e ritmitos silte/argila (d= clastos \\
$\mathrm{Rg}$ & Ritmito lama/areia gradado \\
Dmm & Diamictito maciço \\
$\mathrm{Dms}$ & Diamictito estratificado \\
\hline
\end{tabular}




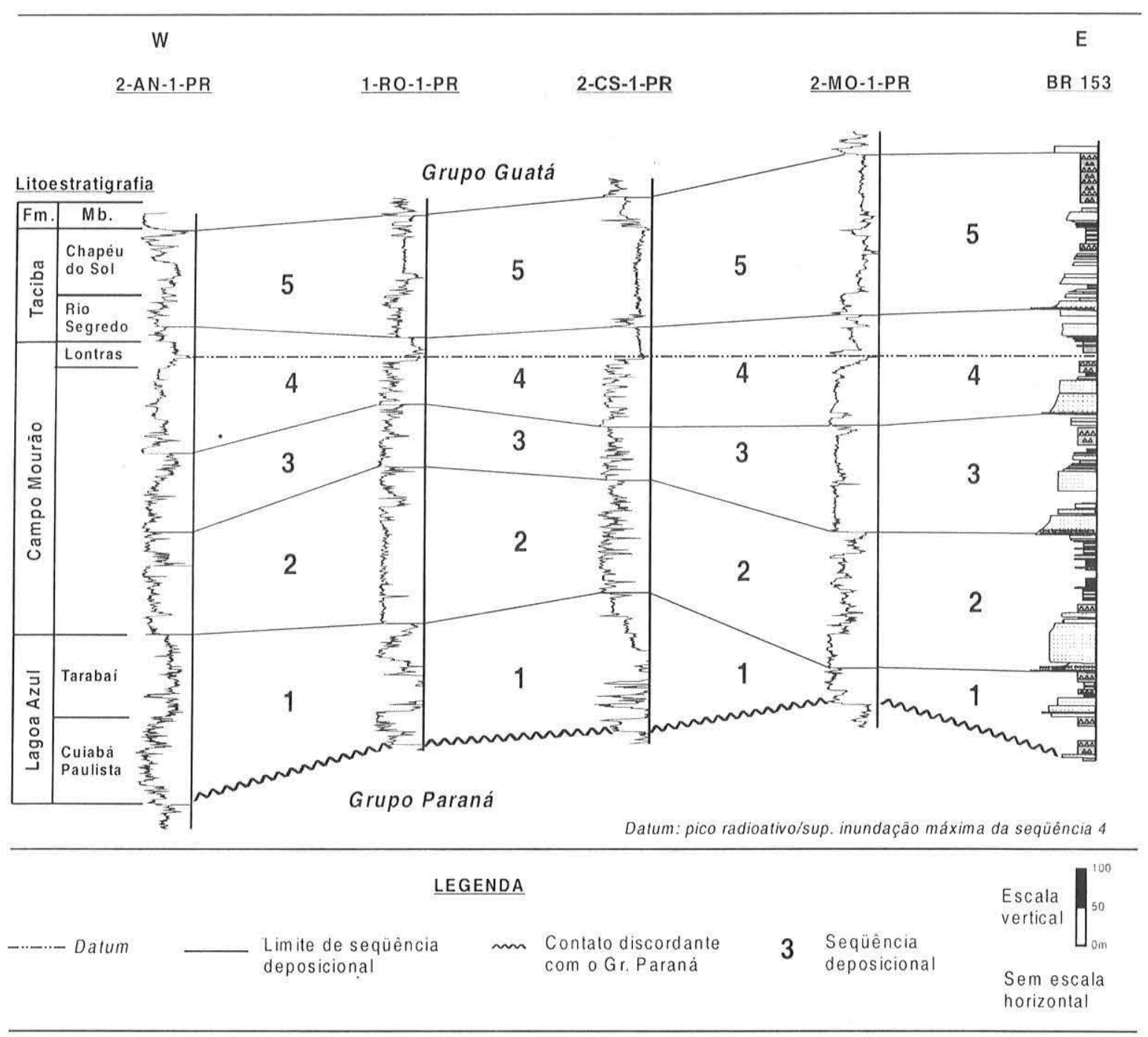

Figura 4 - Correlação estratigráfica do perfil levantado em superfície com perfis de raios-gama de quatro poços perfurados a oeste da área (ver figura 2 para localização). Classificação litoestratigrafia segundo França \& Potter (1988).

forma expressiva na porção inferior da sequiência 1, constituindo espesso pacote de diamictitos. Está presente também na base da sequiência 2, onde restringe-se a um intervalo pouco espesso de diamictitos e a um pavimento de calhaus e matacões (Fig. 5). Não foi constatada nas demais sequiências, onde a associação B ocorre diretamente sobre as disconformidades basais.

Associação B Possui típico e bem desenvolvido padrão de granodecrescência ascendente que culmina em intervalos com alta porcentagem de argila (Fig. 5). Nos perfis de poços, é marcante um progressivo acréscimo de radioatividade para cima, conforme evidenciado nas curvas de raios-gama (Fig. 4). Na parte inferior ocorrem conglomerados desorganizados (fácies Gc), maciços (fácies $(\mathrm{im}$ ) e gradacionais (fácies $\mathrm{Gg}$ ), conglomerados com estratificação cruzada (fácies $\mathrm{Gp}$ ), arenitos com estratificação cruzada (fácies St, Sp e Ss), arenitos maciços (fácies Sm), gradacionais (fácies $\mathrm{Sg}$ ), com estratificação plano-paralela (fácies Sh) e com ondulações de corrente ou com estratificação cruzada cavalgante (fácies Sr) (Fig. 7). Estas fácies apresentam individualmente grande descontinuidade lateral devido ao fato de que se alojam em irregularidades ou canais presentes na base das sequiências, mas no conjunto formam pacotes espessos que se destacam na topografia como relevos escarpados.

No topo da associação B predominam arenitos finos a médios maciços (fácies $\mathrm{Sm}$ ), gradados (fácies $\mathrm{Sg}$ ), com estratificação planoparalela (fácies Sh), com deformação penecontemporânea (fácies Sd) ou ondulações de corrente (fácies $\mathrm{Sr}$ ), definindo corpos de geometria tabular. Associados ocorrem diamictitos maciços (fácies Dmm), ou estratificados (fácies Dms), ritmitos lama/areia gradados (fácies $\mathrm{Rg}$ ) e lamitos/folhelhos (fácies Fl), muitas vezes com clastos caídos (fácies Fld), que ocorrem interestratificados e com recorrência vertical.

Associação C O arranjo vertical é de granocrescência ascendente, bem desenvolvido nas sequiências 2 e 4 e menos perceptível nas demais (Fig. 5). Tal padrão pode ser reconhecido nas assinaturas dos perfis de raios-gama, registrando argilosidade decrescente para cima a partir dos respectivos picos radioativos (Fig. 4). As 


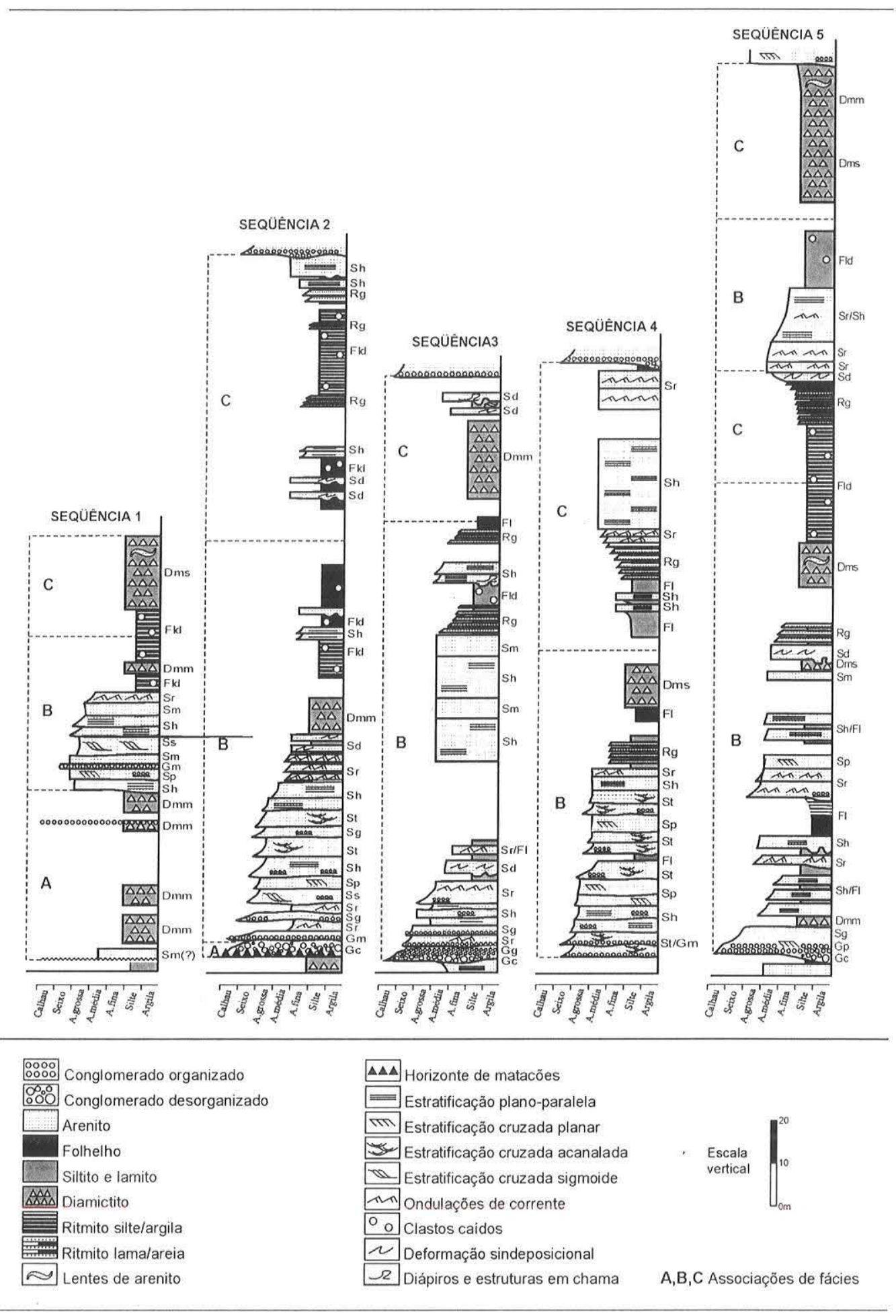

Figura 5 - Perfis estratigráficos ilustrando o arranjo vertical de fácies observado nas cinco seqüências reconhecidas.

fácies predominantes são diamictitos (fácies Dmm/Dms) e ritmitos gradacionais (fácies Rg) (Fig. 8). Também ocorrem arenitos finos a médios com estratificação plano-paralela (fácies Sh), ondulações de corrente (fácies $\mathrm{Sr}$ ) ou deformados (fácies Sd). É marcante a presença de feições de sobrecarga e injeção de lama no contato de arenitos sobre fácies finas, como é o caso dos espetaculares diápiros de folhelho no topo da sequiência 3 (Fig. 8C).

INTERPRETAÇÃO PALEOAMBIENTAL Evidências de influência glacial são encontradas em todas as seqüências, sugerindo que as geleiras estiveram próximas, ou no sítio deposicional durante todo o tempo da sedimentação do Grupo 

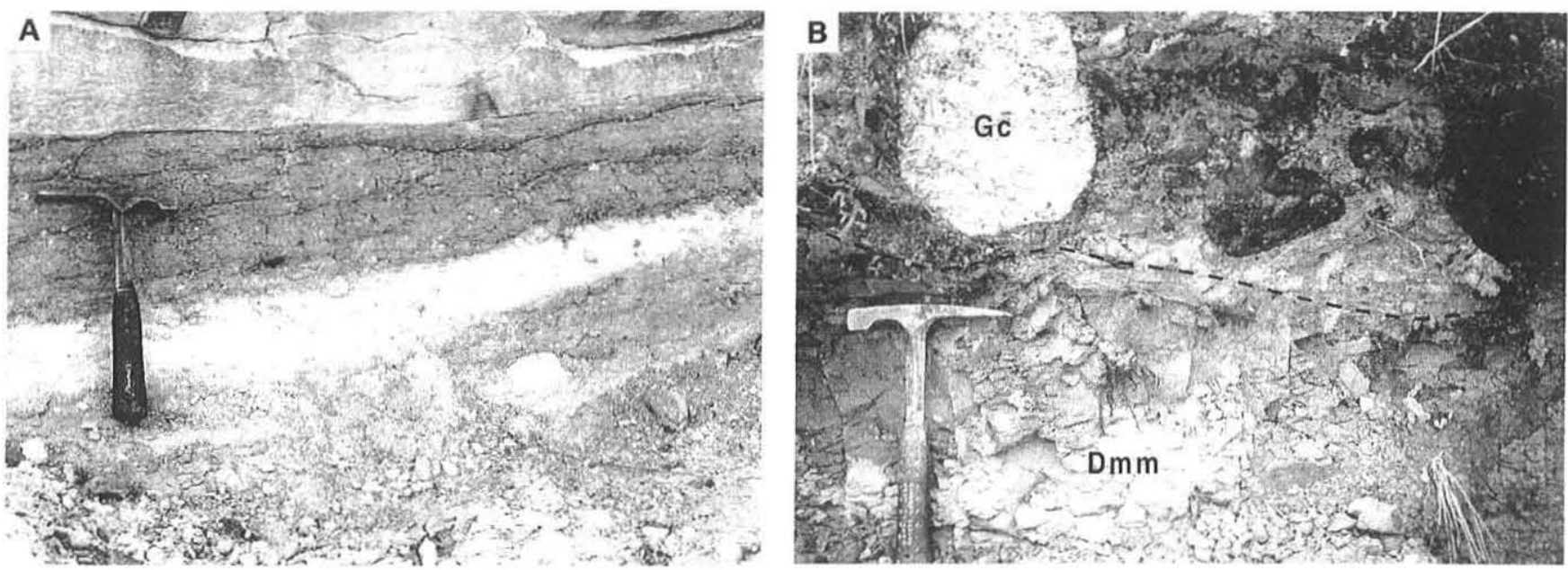

Figura 6 - Fácies sedimentares da associação A: A) diamictito maciço síltico-arenoso; B) conglomerado portador de matacões polimíticos $(G c)$ em contato erosivo sobre diamictitos de sequiência sotoposta (Dmm).
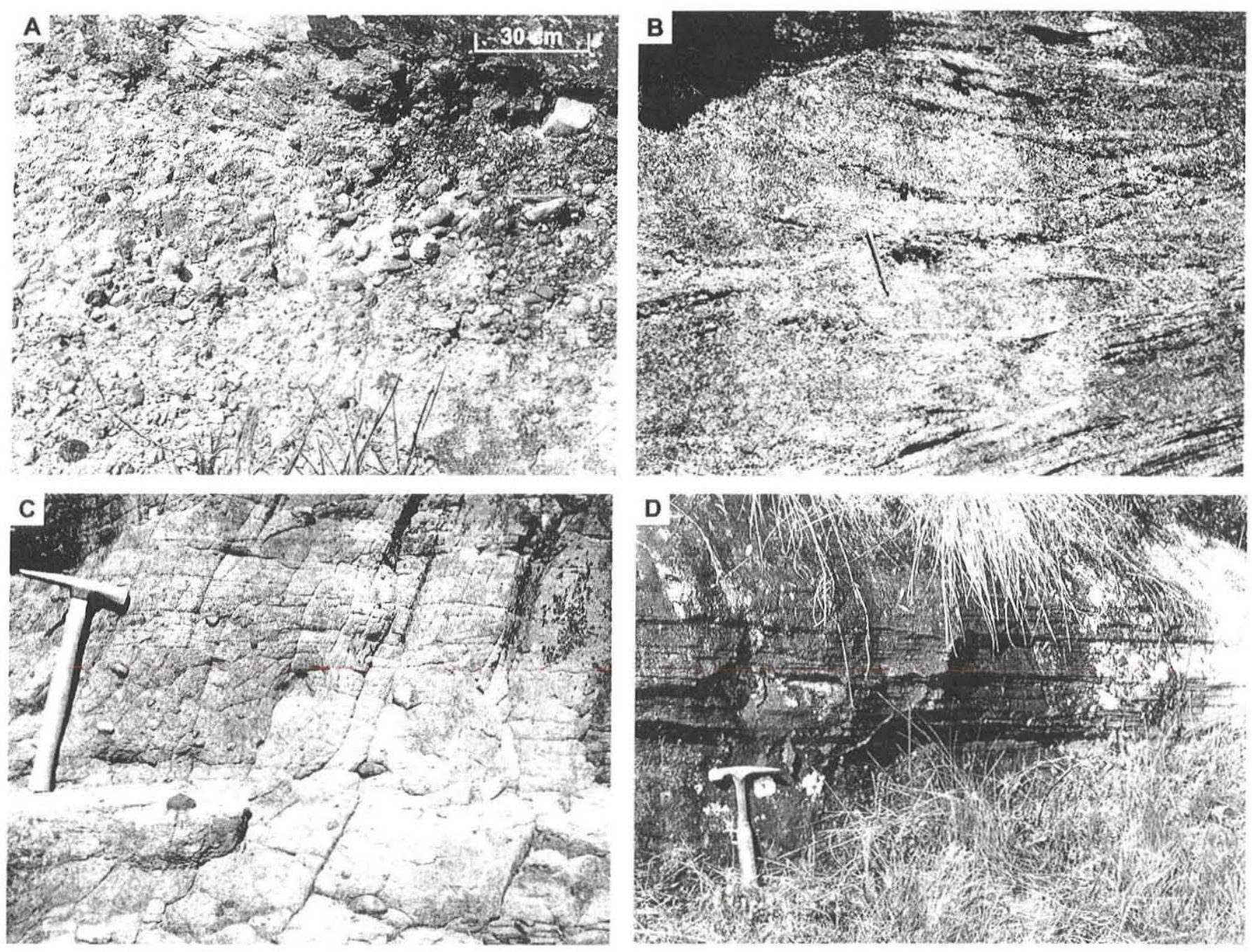

Figura 7 - Fácies sedimentares da associação B: A) conglomerado maciço com imbricação dos eixos maiores dos clastos (lapiseira como escala; fluxo da esquerda para a direita na foto); B) arenito com estratificação cruzada acanalada de médio porte; C) arenito maciço com clastos dispersos; D) arenito com estratificação plano-paralela. 

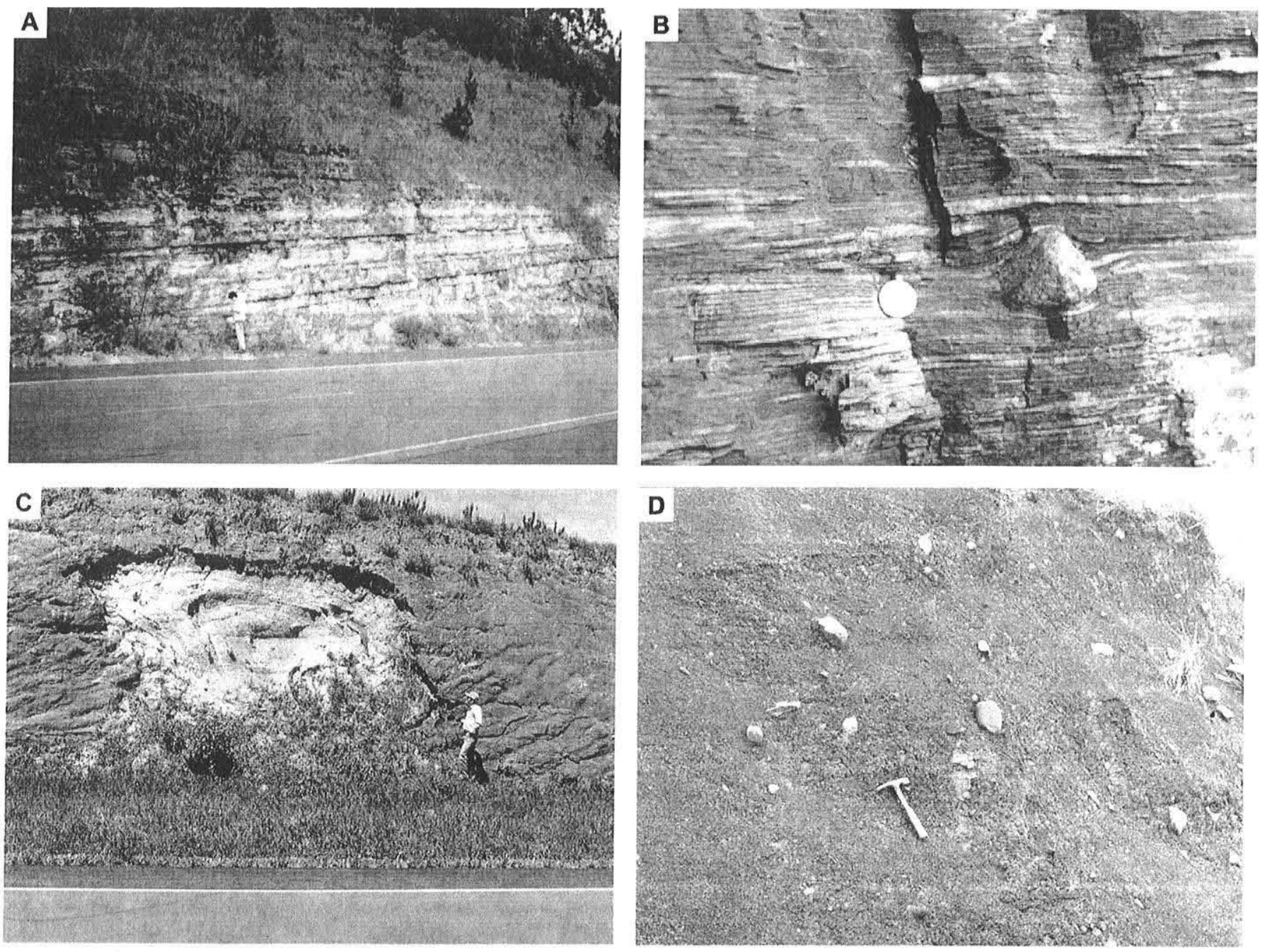

Figura 8-Fácies sedimentares da associação C: A) Ritmito lamítico-arenoso com padrão de granocrescência ascendente; B) clasto caído de gelo flutuante em ritmito siltelargila; $C$ ) estrutura diapírica (folhelhos injetados em arenito conglomerático); D) diamictito maciço a sutilmente estratificado com matriz síltico-argilosa.

Itararé. Diamictitos e conglomerados portadores de clastos facetados e/ou estriados e lamitos com clastos caídos de gelo flutuante são indícios conclusivos da ação de geleiras.

Os sentidos de aporte sedimentar, obtidos a partir da análise de paleocorrentes (Fig. 3) foram preferencialmente para oestenoroeste nas sequiências 1 e 2 e para norte nas seqüências 3,4 e 5. Isso indica fluxos de água de degelo em média para noroeste e centro dispersor de geleiras a sudeste, o que é compatível com reconstruções paleogeográficas regionais.

As associações de fácies sugerem sedimentação predominantemente glácio-marinha para o Grupo Itararé na área estudada, conforme o modelo apresentado na figura 9. Em diamictitos do topo da seqüência 1 foram encontrados esporos de alga marinha do gênero Leiosphaeridia, o que sugere deposição em ambiente glácio-marinho já a partir da seqüência mais antiga do Grupo Itararé. Em fácies da Formação Campo do Tenente na área de Lapa, no sul do Estado do Paraná, cronocorrelatas às da seqüência 1, foram encontrados Tasmanites (França et al. 1996), corroborando a interpretação de ambiente glácio-marinho.

Macrofósseis marinhos não foram encontrados, mas há vários registros em áreas vizinhas. Destacam-se as ocorrências de invertebrados marinhos em Itaporanga (sul do Estado de São Paulo), em Capivari (centro do Estado de São Paulo), em Teixeira Soares, Baitaca e Rio d'Areia (sul do Estado do Paraná) e em Taió e Lontras (Estado de Santa Catarina). Restos de peixes e também braquiópodos ocorrem em Mafra (norte do Estado de Santa Catarina) em nível equivalente à porção média do Grupo Itararé.

Associação A Os diamictitos maciços desta associação foram interpretados como tilitos subglaciais, de acordo com Dreimanis \& Schlüchter (1985) e Miller (1996). Diamictitos maciços, compactados e com feições internas de cisalhamento foram interpretados como tilitos de alojamento (lodgement tillite), que são formados na base de geleiras num processo que envolve intensa abrasão dos clastos transportados, entre si e com o substrato. Diamictitos com menor grau de compactação e sem indícios de cisalhamento foram considerados tilitos de ablação ou de degelo (melt-out tillite), cuja gênese se dá de modo passivo durante o processo de ablação da geleira (perda de massa).

Os depósitos subglaciais podem estar restritos a apenas um 


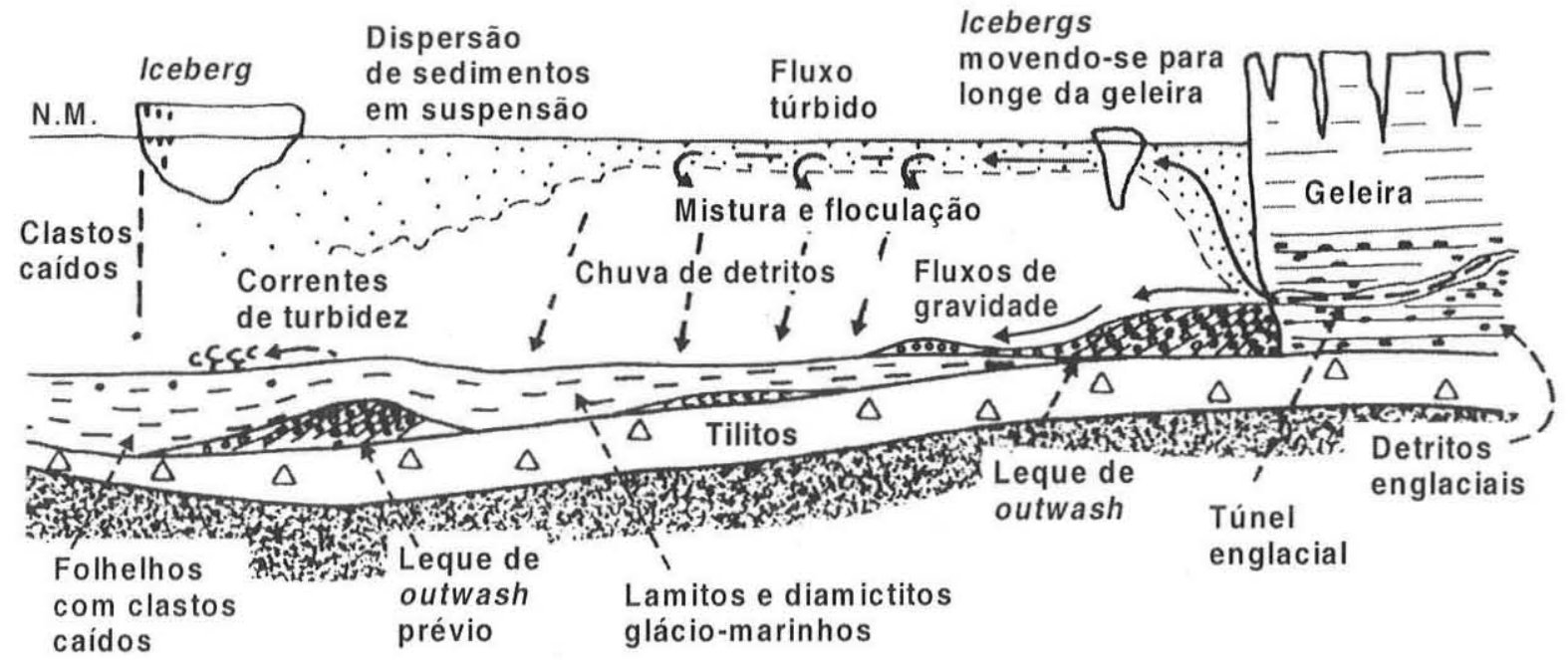

Figura 9-Modelo genérico ilustrando os processos sedimentares predominantes durante a sedimentação do Grupo Itararé em ambiente glácio-marinho (modificado de Boulton \& Deynoux 1981).

delgado horizonte de matacões polimíticos (pavimento de clastos), como ocorre na base da sequiência 2. Exemplos desses pavimentos na Bacia do Paraná foram documentados por Rocha-Campos et al. (1976) no Estado de São Paulo.

Corpos lenticulares e pouco espessos de conglomerados mal selecionados, de aspecto caótico, portadores de matacões polimíticos e que ocorrem intercalados aos tilitos, representam sedimentos glaciais remobilizados por correntes de água de degelo subglacialmente (eskers) ou depósitos de boca de túnel (conforme modelo de Powell \& Molnia 1989).

Associação B A associação é interpretada como produto de sedimentação em sistemas de leques proglaciais subaquosos de outwas $h$, cuja retração em virtude do recuo da geleira desenvolve empilhamento retrogradacional (Rust \& Romanelli 1975). Leques proglaciais são sistemas comuns nas margens de geleiras em contexto terrestre ou subaquoso e são testemunhas da alta taxa de sedimentação destes ambientes (Boulton 1986, Martini 1990).

Conglomerados e arenitos com estratificação cruzada (fácies Gm, Gg, Gp, Sp e St) constituem a base de pequenos ciclos com granodecrescência ascendente na parte inferior da associação. Representam pacotes com base canalizada escavando fácies mais finas, o que sugere deposição nos canais distributários dos leques. A sedimentação ocorre em eventos episódicos durante o recuo das geleiras, quando há saída de fluxos de água confinada no interior ou na base do gelo. No registro geológico, arenitos e conglomerados originados em leques de outwash subaquosos foram identificados por Visser et al. (1986) em sucessões glaciais do neopaleozóico gonduânico da África do Sul (Grupo Dwyka).

Arenitos maciços e laminados registram deposição subaquosa sob condições não-confinadas, através de ressedimentação gravitacional por fluxos liquefeitos em áreas intercanais ou em lobos (Lowe 1982). Esses fluxos podem evoluir para turbiditos de alta densidade à medida em que há modificação, gradiente abaixo, no mecanismo de suporte do fluxo. Feições de deformação penecontemporânea sugerem processos de escorregamento/ deslizamento de massa nos foresets íngremes dos leques de outwash (conforme LÆnne 1995).

Parte do fluxo que penetra no corpo d'água comporta-se como uma pluma (fluxo hipo/homopicnal), mantendo em suspensão a carga sedimentar mais fina. A decantação desta pluma e a eventual queda de clastos de icebergs, num processo denominado chuva de detritos (rain out), pode originar diamictitos maciços a ligeiramente estratificados (fácies Dmm/Dms).

$\mathrm{O}$ recobrimento dos arenitos e conglomerados de outwash por fácies mais finas da associação B (fácies Dms e Rg) indica retração dos sistemas de leques de subaquosos devido ao recuo da margem da geleira e sedimentação por fluxos de detritos e correntes de turbidez, sendo comum processos de remobilização e ressedimentação. Lamitos (fácies Fl/Fld) registram deposição lenta do material fino em suspensão nas franjas dos lobos e porções distais. Contribuição de material mais grosso decantado do derretimento de icebergs são responsáveis pela presença de fácies de granulação fina com clastos caídos (Fld), que se intercalam aos diamictitos, ritmitos e lamitos. Folhelhos representam as fácies com menor influência glacial, sendo formados a partir da decantação de argilas em suspensão.

Associação C Ritmitos gradados, aos quais ocorrem associados arenitos maciços e arenitos laminados, são variedades de fácies produzidas por correntes de turbidez, portanto inseridas em um mesmo contexto deposicional. Diamictitos produzidos por chuva de detritos e fluxos de detritos coesivos compõem um quadro onde predominam processos gravitacionais subaquosos, inclusive com remobilização talude abaixo por escorregamentos e/ou deslizamentos de massa.

Geneticamente, portanto, as fácies assemelham-se àquelas da parte superior da associação B. No entanto, o empilhamento com granocrescência ascendente representa uma mudança no padrão de sedimentação, possivelmente conseqüência da progradação dos leques subaquosos prenunciando o início de novo ciclo glacial.

TRATOS DE SISTEMAS DEPOSICIONAIS As cinco seqüências deposicionais são limitadas por disconformidades que possivelmente passam para conformidades lateralmente para o interior da bacia. Os limites de sequiência (LS I a 5) são superfícies erosivas, marcadas pela entrada de clásticos grossos na bacia e geradas pelo avanço de geleiras durante os picos glaciais. As 
sequiências possuem arranjos verticais de fácies e tratos deposicionais semelhantes, com típico padrão retrogradacional na parte inferior (associação B) e, por vezes, empilhamentos progradacionais na parte superior (associação C), ora mais ora menos preservados (Figs. 3, 4 e 5).

Os limites entre as associações B e C estão situados nos intervalos mais ricos em fácies argilosas, correspondentes a máximos de radioatividade em perfis de raios-gama, separando padrões retrogradacionais abaixo de padrões progradacionais acima. Como proposto no modelo de Martini \& Brookfield (1995), essas superfícies representam afogamento dos sistemas de outwash, devido ao progressivo recuo da margem da geleira e consequiente distanciamento da "área-fonte" (ponto de injeção de sedimentos). Correspondem a épocas de mínimo glacial e conseqüente diminuição no aporte sedimentar, representando momentos de elevação relativa local do nível do mar (superfícies de inundação máxima).

A superfície de inundação máxima que apresenta maior continuidade lateral está situada na seqüência 4, tendo sido por isso utilizada como datum na seção estratigráfica apresentada na figura 4. O intervalo é rico em folhelhos e pode ser reconhecido até o Estado de Santa Catarina, correspondendo ao que litoestratigraficamente tem sido denominado de Membro Lontras (Castro 1999).

A arquitetura interna das seqüências compreende tratos de sistemas deposicionais (Posamentier et al. 1988). Considerando, entretanto, o fato de que numa bacia glaciada não há sincronismo entre os eventos nas bordas com geleiras e nas bordas sem geleiras, pois na primeira existe também a atuação de fenômenos glácioisostáticos, a aplicação dos modelos clássicos de tratos de sistemas deve ser feita com reservas, buscando-se terminologia própria já que a lógica do preenchimento sedimentar não é puramente eustática e/ou tectônica.

Para efeito de análise neste trabalho, os tratos de sistemas serão discutidos tendo por base as três associações descritas, uma vez que as mesmas têm conotação genética como padrão de preenchimento sedimentar. Para tal, serão tratadas a seguir como tratos: glacial máximo (associação A), de deglaciação (associação B) e de avanço glacial (associação C).

Trato glacial máximo Caracterizado pela presença de fácies subglaciais, que ocorrem na parte inferior das sequêencias. Representado por tilitos e fácies associadas, tais como conglomerados portadores de matacões polimíticos. Fácies subglaciais não foram constatadas na base das seqüências 3,4 e 5 , mas a existência de conglomerados imaturos com matacões decimétricos de granito, constatados na base das seqüências $3 \mathrm{e}$ 5 , sugere retrabalhamento de depósitos subglaciais por água de degelo. Por isso, tilitos podem ocorrer em outras seções, onde tenham sido preservados do retrabalhamento.

O trato glacial máximo compreende os depósitos formados nos momentos em que a geleira mais avançou no sítio de sedimentação, com o desenvolvimento de complexos sistemas deposicionais subglaciais ou proglaciais de contato glacial.

Depósitos subglaciais foram considerados por Martini \& Brookfield (1995) e Brookfield \& Martini (1999), como tratos de sistemas de mar/lago baixo (lowstand systems tracts), pois a sedimentação processa-se em contexto proximal à geleira. Nesse caso, os autores consideram como principal fator controlador da arquitetura estratigráfica local a posição da margem da geleira e não a lâmina d'água.
Trato de deglaciação Trato cuja denominação foi adaptada de terminologia proposta por Visser (1997), é caracterizado por empilhamento retrogradacional cujo padrão é equivalente ao de um trato de sistemas transgressivo (transgressive system tract). A retração dos leques de outwash acompanha o recuo da margem da geleira, pois o ponto de injeção de sedimentos distancia-se cada vez mais do sítio deposicional (Cheel \& Rust 1986, Martini \& Brookfield 1995, Brookfield \& Martini 1999). O aumento da taxa de suprimento sedimentar derivado do degelo é superado pela geração de espaço de acomodação na margem da geleira, consequêencia de subida glácio-eustática e depressão glácio-isostática. Isso promove o recobrimento das fácies de outwash por turbiditos e lamitos marinhos distais, até se atingir valor máximo de argilosidade (superfície de inundação máxima).

Nos estágios iniciais de degelo, com margem de geleira retrátil ou estacionária, foram depositados espessos pacotes arenoconglomeráticos altamente instáveis e suceptíveis a remobilização por eventos subseqüentes de deslizamento e escorregamento de massa, que evoluiram bacia adentro para correntes de turbidez de alta e baixa densidades. A deposição ocorreu por fluxos episódicos de água de degelo, o que gerou sobrecarga sobre sedimentos das seqüências sotopostas saturados em água, produzindo uma variada gama de feições deformacionais.

A existência de clastos caídos, verificados em abundância nas fácies finas das seqüências 1,2 e 5 , requer forte influência de plataformas de gelo flutuantes ou icebergs. Isso significa que mesmo nos estágios de mínimo glacial, provavelmente o gelo ainda mantinha contato com o corpo d'água.

Trato de avanço glacial A terminologia adotada para este trato foi adaptada de Brookfield \& Martini (1999). Compreende as sucessões progradacionais presentes na parte superior de algumas sequêencias, depositadas em condições distais em relação à geleira que avança. Como esse trato é limitado no topo por disconformidade (avanço glacial), sua parte superior pode estar incompleta devido à erosão.

Progradação de sistemas subaquosos em eventos de avanço glacial devem ser atribuídos ao caráter oscilatório do avanço da geleira, havendo interferência de pulsos de degelo de menor amplitude, com deposição de sedimentos à sua frente, mesmo quando a tendência geral da geleira é de avançar.

Outra hipótese plausível seria a existência de tratos de mar alto, devido ao recuo da margem da geleira para o continente e progradação de deltas proglaciais. No entanto, fácies dessa natureza deveriam ser encontradas mais a sul, em áreas proximais em relação à seção analisada neste trabalho.

Sucessões semelhantes ocorrem no Grupo Itararé, no sul do Paraná e norte de Santa Catarina (Canuto et al. 2001). Os autores as denominaram de "trato de sistemas regressivo glácio-isostático", admitindo sua gênese associada a eventos de reajuste glácioisostático. Na area estudada não foram verificadas, no entanto, feições indicativas de ambiente raso, tais como retrabalhamento por ondas e superfícies de exposição aérea, que são características nas sequiências de emergência glácio-isostática descritas por McCabe et al. (1994) e Syvitski \& Lee (1997) para o Pleistoceno.

CONCLUSÕES A aplicação de conceitos de Estratigrafia de Seqüências na análise estratigráfica do Grupo Itararé permitiu que fossem reconhecidas cinco sequiências deposicionais limitadas por disconformidades. As seqüências possuem padrão vertical 
retrogradacional-progradacional, nem sempre completo, e são produto de ciclos de avanço e recuo de geleiras em ambiente glácio-marinho.

A integração de dados de superfície com os de subsuperfície mostrou que as sequiências possuem representatividade regional ao longo de uma seção construída aproximadamente no strike deposicional. Mostrou também que a classificação litoestratigráfica concebida para o interior da bacia pode ser aplicada satisfatoriamente na faixa aflorante.

Do ponto de vista conceitual, ficou evidente que os modelos de tratos de sistemas deposicionais propostos para bacias marginais não glaciadas não se ajustam adequadamente ao registro sedimentar das seqüências glaciais, havendo necessidade de adaptação e proposição de novos modelos.

$\mathrm{Na}$ Bacia do Paraná, o recuo definitivo das geleiras foi seguido de expressivo soerguimento glácio-isostático na porção norte da bacia devido ao alívio da carga do gelo, o que causou erosão e incisão de vales, gerando uma disconformidade de topo sobre a qual desenvolveram-se os sistemas flúvio-deltaicos da Formação Rio Bonito.

Agradecimentos À FAPESP pela concessão de bolsa de mestrado e recursos de reserva técnica ao primeiro autor (processo 99/045593) e apoio financeiro a projeto de pesquisa coordenado pelo segundo autor (processo 98/02183-3). Aos revisores da RBG pelas sugestões ao manuscrito.

\section{Referências}

Assine M.L. 1996. Aspectos da estratigrafia das seqüências précarboníferas da Bacia do Paraná no Brasil. Tese de Doutoramento, Instituto de Geociências, Universidade de São Paulo, 207 p.

Boulton G.S. 1986. Push moraines and glacier-contact fans in marine and terrestrial environments. Sedimentology, 33:677-698.

Boulton G.S. \& Deynoux M. 1981. Sedimentation in glacial environments and the identification of tills and tillites in ancient sedimentary sequences. Precambrian Research, 15:397-422.

Brookfield M.E. \& Martini I.P. 1999. Facies architecture and sequence stratigraphy in glacially influenced basins: basic problems and waterlevel/glacier input-poin controls (with a exemple from the Quaternary of Ontario, Canada). Sedimentary Geology, 123:183-197.

Canuto J.R., Santos P.R., Rocha-Campos A.C. 2001. Estratigrafia de seqüências do Subgrupo Itararé (Neopaleozóico) no leste da Bacia do Paraná, nas regiões sul do Paraná e norte de Santa Catarina, Brasil. Rev. Bras. Geoc., 31:107-116

Castro J.C. 1999. Estratigrafia de sequiências das formações Campo Mourão (parte superior) e Taciba, Grupo Itararé, leste da Bacia do Paraná. Rev. Bras. Geoc., 29:255-260.

Cheel R.J. \& Rust B.R. 1986. A sequence of soft-sediment deformation (dewatering) structures in Late Quaternary subaqueous outwash near Ottawa, Canada. Sedim. Geol., 47:77-93.

D'Ávila R.S.F. 1999. Análise de Fácies e Estratigrafia Física do Arenito Lapa, Grupo Itararé, Bacia do Paraná, Brasil. Dissertação de Mestrado, Instituto de Geociências, Universidade Federal do Rio Grande do Sul, 349 p.

Dreimanis A. \& Schluichter C. 1985. Field criteria for the recognition of till or tillite. Palaeogeog., Palaeoclimat., Palaeoeco., 51:7-14.

Eyles N., Eyles C.H., França A.B. 1993. Glaciation and tectonics in an active intracratonic basin : The Late Paleozoic Itarare Group, Paraná Basin, Brazil. Sedimentology, 40:1-25.

Eyles N., Eyles C.H., Miall A.D. 1983. Lithofacies types and vertical profile models: an alternative approach to the description and environmental interpretation of glacial diamict and diamictite sequences. Sedimentology, 30:393-410.

França A.B. \& Potter P.E. 1988. Estratigrafia, ambiente deposicional e análise de reservatório do Grupo Itararé (Permocarbonífero), Bacia do Paraná (parte 1). Bol. Geoc. Petrobrás, 2:147-191.

França A.B., Winter W.R., Assine M.L. 1996. Arenitos Lapa-Vila Velha: Um modelo de trato de sistemas subaquosos canal-lobos sob influência glacial, Grupo Itararé (C-P), Bacia do Paraná. Rev. Bras. Geoc., 26: 43-56.

LÆnne I. 1995. Sedimentary facies and depositional architecture of icecontact glaciomarine systems. Sedim. Geol., 98:13-43.

Lowe D.R. 1982. Sediment gravity flows: II. depositional models with special reference to the deposits of high-density turbidity currents. J. Sed. Pet., 52:279-297.

Martini I.P. 1990. Pleistocene glacial fan-deltas in southern Ontario, Canada. In: A. Colella \& D. B. Prior (eds.) Coarse-Grained Deltas. Oxford. IAS/Blackwell Scientific Publications. pp.: 281-295.

Martini I.P. \& Brookfield M.E. 1995. Sequence analysis of Upper Pleistocene (Wisconsinan) glaciolacustrine deposits of the NorthShore Bluffs of Lake Ontario, Canadá. Journal of Sedimentary Research, B65:388-400.

McCabe A.M., Carter R.W.G., Haynes J.R. 1994. A shallow marine emergent sequence from the northwestern sector of the last British ice sheet, Portballintrae, Northern Ireland. Marine Geology, 117:1934 .

Milani E.J., Faccini U.F., Scherer C.M., Araujo L.M., Cupertino J.A. 1998. Sequences and stratigraphic hierarchy of the Paraná Basin (Ordovician to Cretaceous), southern Brazil. Bol. Inst. Geoc. da Universidade de São Paulo, 29:125-173.

Milani E.J., França A.B., Schneider R.L. 1994. Bacia do Paraná. Rev. Bras. Geoc., 8:69-82.

Miller J.M.G. 1996. Glacial Sediments. In: H.G. Reading (ed.) Sedimentary Environments: Processes, Facies and Stratigraphy. Oxford. Blackwell Science, pp.: 454-484.

Posamentier H.W., Jervey M.T., Vail P.R. 1988. Eustatic control on clastic deposition I - conceptual framework. In: C.K. Wilgus et al. (ed.) Sea-level Changes: an Integrated Approach. Tulsa. Society of Economic Paleontologists. pp.: 110-124.

Powell R.D. \& Molnia B.F. 1989. Glacimarine sedimentary processes, facies, and morphology of the south-southest Alaska Shelf and fjords. Marine Geol., 85:359-390. 
Rocha-Campos A.C., Oliveira M.E.C.B., Santos P.R., Saad A.R. 1976. Boulder pavements and the sense of movement of late paleozoic glaciers in central eastern São Paulo State, Paraná Basin, Brazil. Bol. Inst. Geoc. da Universidade de São Paulo, 7: 149-160.

Rust B.R. \& Romanelli R. 1975. Late Quaternary subaqueous outwash deposits near Ottawa, Canada. In: A.V. Jopling \& B.C. McDonald (ed.) Glaciofluvial and Glaciolacustrine Sedimentation. Tulsa. Society of Economic Paleontologists. pp.: 177-192.

Santos P.R., Rocha-Campos A.C.,Canuto J.R. 1996. Patterns of Late Palaeozoic deglaciation in the Paraná Basin, Brazil. Palaeogeog., Palaeoclim., Palaeoeco., 125:165-184.

Souza P.A. 2000. Palinobioestratigrafia do Subgrupo Itararé, Carbonífero/Permiano, na porção nordeste da Bacia do Paraná (SP/PR, Brasil). Tese de Doutoramento, Instituto de Geociências, Universidade de São Paulo, 197 p.

Syvitski J.P.M. \& Lee H.J. 1997. Postglacial sequence stratigraphy of Lake Melville, Labrador. Marine Geology, 143:55-79.

Vail P.R., Mitchum R.M.J., Todd R.G., Widmier J.M., Thompson I.S.,
Sangree J.B., Bubb J.N., Hatlelid W.G. 1977. Seismic stratigraphy and global changes of sea level. In: C. Payton (ed.) Seismic Stratigraphy: Applications to Hydrocarbon Exploration. Tulsa. AAPG. pp.: 49-212.

Vesely F.F. 2001. Análise de Sequiências em Sucessões Glaciais: Estudo de Caso no Grupo Itararé (C-P), Nordeste do Estado do Paraná. Dissertação de Mestrado, Instituto de Geociências e Ciências Exatas, Universidade Estadual Paulista, 119 p.

Visser J.N.J. 1997. Deglaciation sequences in the Permo-carboniferous Karoo and Kalahari basins of southern Africa: a tool in the analysis os cyclic glaciomarine basin fills. Sedimentology, 44:507-522.

Visser J.N.J., Loock J.C., Colliston W.P. 1986. Subaqueous outwash fan and esker sandstones in the permo-carboniferous Dwyka Formation of South Africa. J. Sed. Pet., 57:467-478.

Manuscrito A-1411

Recebido em 20 de fevereiro de 2003

Revisão dos autores em 15 de março de 2004 Revisão aceita em 30 de março de 2004 